\title{
Aquífero costeiro de Icapuí, Ceará, Brasil: uma proposta de avaliação ambiental
}

A cidade de Icapuí, localizada na parte mais oriental do litoral do Estado do Ceará, nordeste do Brasil, foi classificada, no último zoneamento econômico-ecológico costeiro (ZEE), como polo de interesse ecológico da região e, dobrou o Índice de Desenvolvimento Humano Municipal (IDHM), nas últimas duas décadas. Com uma população ativa, economicamente, em torno de $70 \%$, mais de $90 \%$ destes estão envolvidos com a cadeia produtiva da lagosta. Destaque nas atividades econômicas do município vão para o turismo comunitário, a agricultura e a aquicultura. Busca-se, neste estudo, subsidiar ações de políticas públicas, por meio de estudos de vulnerabilidade do aquífero, voltadas para melhorar a condição de vida e a valoração dos recursos naturais. Por meio de construção de matriz de valoração de impactos ambientais e, agregando outros valores intangíveis da biodiversidade, conclui-se que as riquezas naturais e o saber popular, podem ser melhor utilizados com uma maior participação de órgãos públicos e empresas privadas, proporcionando linhas de créditos mais específicas e presença de consultorias especializadas. Tais observações/sugestões, devidamente estudadas e implantadas, permitiriam um crescimento da localidade, sem perder a classificação de polo de interesse ecológico.

Palavras-chave: Economia Ecológica; Recursos Naturais; Vulnerabilidade de Aquífero; Avaliação Ambiental; Icapuí/Brasil.

\section{The Icapui coast aquifer, Ceará, Brazil: a proposal for environmental evaluation}

\begin{abstract}
The city of Icapuí, located in the eastern side of the coast of the State of Ceará, northeastern Brazil, it was classified in the last the ZEE, like as an area of ecological interest in the region and, also, it doubled the Human Development Index (IDH) in the last two decades. It has a economically active population to around $70 \%$, and than, more $90 \%$ of these are involved with the production chain of the lobster. It is economic activities high performance, for example, community tourism, agriculture and aquaculture. In this study, we seek to subsidize public policy actions, through aquifer vulnerability studies, aimed at improving the living conditions and valuation of natural resources. After by constructing an environmental impact assessment matrix for this aquifer, and, adding intangible values that biodiversity has for this matrix, it was concluded that, this natural wealth more the people knowledge, will can be better used, since that, the Governement, and Private Companies, it was can going to increase participation, like, for example, providing to lines of more specific credits and the presence of specialized consultants. Such observations and suggestions, duly studied and implemented, would allow for the growth of the locality, without losing the status of the friendly environmental region.
\end{abstract}

Keywords: Ecological Economics; Natural Resource; Aquifer Vulnerability; Environmental Evaluation; Icapui/Brazil.

Topic: Sistemas de Gestão Ambiental

Reviewed anonymously in the process of blind peer
Received: 20/03/2017

Approved: 19/05/2017
Saulo Roberio Rodrigues Maia

Universidade Federal do Ceará, Brasil

http://lattes.cnpq.br/2357110960992983

saulo.maia@uece.br

George Satander Sá Freire

Universite de Nantes, França

http://lattes.cnpq.br/6803944360256138

satanderfreire@gmail.com

Diolande Ferreira Gomes

Universidade Federal do Ceará, Brasil

http://lattes.cnpq.br/0048357648552119

dfreire68@gmail.com
Referencing this:

MAIA, S. R. R.; FREIRE, G. S. S.; GOMES, D. F.. Aquífero costeiro de Icapuí, Ceará, Brasil: uma proposta de avaliação ambiental. Revista Ibero-Americana de Ciências Ambientais, v.8, n.3, p.254-267, 2017. DOI: http://doi.org/10.6008/SPC2179-6858.2017.003.0023 


\section{INTRODUÇÃO}

Mudanças ambientais visualizadas pela alteração do cenário e que causam certo desconforto climático, por seu turno, alterando atividades humanas como, técnicas e práticas de cultivo, pastoreio e lazer, são bastante retratadas e difundidas nos meios acadêmicos e pela mídia em geral. Metade da quantidade de água potável no mundo, aproximadamente $15.300 .000 \mathrm{~km}^{3}$, está presente na parte subterrânea da Terra e, cerca de $0,6 \%$ do abastecimento total de água do mundo se encontra nas águas subterrâneas (BAIRD et al., 2011). Por ser conhecidamente de melhor qualidade, se comparada à água superficial, e de baixo custo, têmse uma política de exportação mundial crescente dessas águas, cerca de 1,5bi de pessoas no globo usam esta fonte. Inclusive na América do Sul, tendo como justificativa atender as necessidades sociais e econômicas (BOCANEGRA, 2010).

Entretanto, em caso de extração excessiva do recurso mineral e concentrada, pode-se ter problemas graves como: a intrusão salina, a subsidência do solo e o rebaixamento do nível freático (ALIEVI, 2012). Observa-se ainda uma competição pelo uso da água doce, devido às disputas geradas pelos desenvolvimentos urbano, industrial, agrícola (esse chega a consumir de 60 a 80\%), ocasionando assim, uma diminuição da disponibilidade do recurso natural para o uso doméstico (AUGUSTO et al., 2012).

Contando com uma população que se aproxima dos 20 mil habitantes e com mais de 5.200 residências permanentes, o município de Icapuí tem na gestão da oferta d'água e na ausência da rede coletora de esgoto problemas pontuais de destaque. Enquanto a oferta de serviços de abastecimento de água pela rede geral de distribuição alcança $91,10 \%$ das residências do município com o restante das moradias abastecidas por poço ou nascente na propriedade, sendo que $100 \%$ da água distribuída é de origem subterrânea.

Com relação ao esgotamento sanitário, apenas 29, deste universo de 5.200 habitações, estão ligadas à rede geral de esgotos ou à rede de drenagem pluvial, com outras 753 residências servidas por fossa séptica (IPECE, 2016). Outra atividade que se utiliza, de forma bastante intensa, dos recursos hídricos da região é a carcinicultura. $\mathrm{O}$ cultivo de camarão em tanques necessita a retirada de parte da água doce local e, que após o seu uso é descartada de volta, com o devido tratamento do efluente.

Para garantir tais obrigações, são exigidas por parte dos órgãos ambientais, análises físicas, químicas e biológicas da água que entra na fazenda e da sua saída, visto que os rejeitos do animal mais a ração e as espécies mortas produzem um aumento do teor de matéria orgânica no corpo hídrico, tal material particulado no rio pode capturar metais presentes por emissão dos efluentes domésticos, como zinco e cobre, e num processo de retroalimentação, voltar ao tanque da fazenda e ser assimilado pelo camarão (LACERDA et al., 2004). Este trabalho visa subsidiar ações de políticas públicas, por meio de estudos de vulnerabilidade do aquífero, voltadas para melhorar a condição de vida e a valoração dos recursos naturais. 


\section{REVISÃO TEÓRICA}

\section{Aquífero costeiro}

Aquífero é uma formação geológica que permite a circulação de água através de seus poros ou fissuras, permitindo o uso desta água pelo homem em quantidades econômicas significativas para satisfazer as suas necessidades (CUSTÓDIO et al., 1983). A descarga da água subterrânea nas águas de superfície é conhecida como escoamento básico, permitindo que o nível da água nos lagos e rios não diminuam na estiagem

Os aquíferos podem ser classificados de acordo com a pressão hidrostática da água nas suas superfícies, em: confinados, drenantes ou não drenantes e livres, conforme se visualiza na figura 1. Aquíferos confinados são aqueles em que a sua água está sob pressão maior do que a atmosférica. Aquíferos confinados não drenantes: possui camadas limítrofes totalmente impermeáveis, não permitindo, assim, que haja fluxo entre as diferentes camadas. Aquíferos confinados drenantes: possuidores de, pelo menos, uma das camadas confinantes semipermeáveis, permitindo a existência de fluxo entre as diferentes camadas. Este fluxo é nomeado de drenança, podendo ser ascendente ou descendente.

Aquíferos livres ocorrem próximo à superfície topográfica, tendo como limite superior a superfície freática, e a pressão pontual neste limite é igual à pressão atmosférica. Assim como os aquíferos confinados, podem ser drenantes ou não drenantes. A distribuição de um aquífero, em um sistema geológico, é controlada por fatores como: composição mineral (litologia); relações geométricas e cronológicas entre seus constituintes (estratigrafia) e características geométricas como produto de deformações (estrutura) (MANOEL FILHO, 2008)

Em aquíferos costeiros, onde predomina sedimentos inconsolidados, e com o transporte de areias eólicas que se caracterizam pela ausência de siltes e argilas, tem-se favorecido, em escala local e até regional, uma granulometria e textura dos sedimentos homogênea. Sendo de permeabilidade moderável $\left(10^{-4}\right.$ a $10^{-6}$ $\mathrm{m} / \mathrm{s}$ ) e porosidade entre 30 a $45 \%$, formando aquíferos em locais com espessura suficiente.

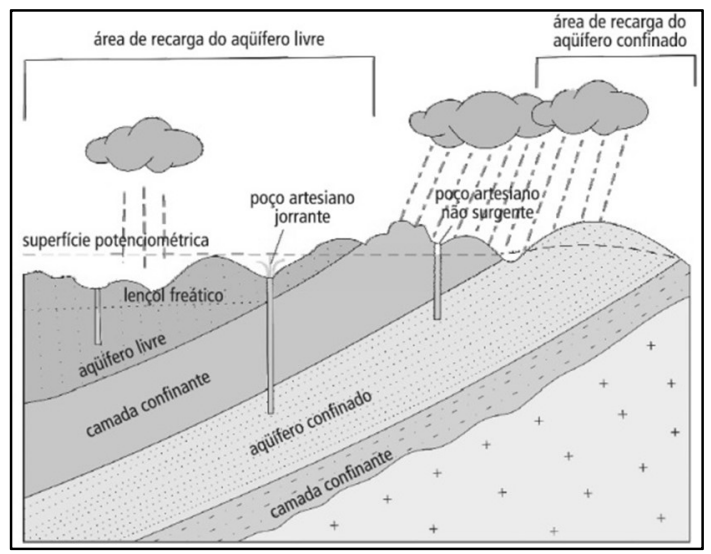

Figura 1: Aquífero livre e aquífero confinado.

Estudo relacionando água doce com água salgada vem desde o final do século XIX e tem ganhado força ultimamente devido ao crescimento demográfico na zona costeira, levando assim a grande demanda por explotação de águas subterrâneas. Controlar a intrusão marinha no aquífero costeiro é objeto de 
pesquisas no mundo, utilizar o recurso mineral sem contaminar o aquífero com água do mar, atraindo a cunha salina (figura 2), dá-se pela compreensão desta zona de transição (mistura entre água doce e salgada).

O bombeamento deve ser controlado levando em conta o cone de rebaixamento, visto que a interfase marinha varia com as flutuações do nível do aquífero, amplitude da maré, pluviometria e outros. Essas interações entre cátions e ânions presentes nos dois ambientes podem ser relacionadas por razões entre concentrações, em meq. $\mathrm{L}^{-1}$, de íons como: $\left[\mathrm{Mg}^{2+}\right] /\left[\mathrm{Ca}^{2+}\right] ;\left[\mathrm{K}^{+}\right] /\left[\mathrm{Na}^{+}\right] ;\left[\mathrm{Cl}^{-}\right] /\left[\mathrm{CO}_{3} \mathrm{H}^{-}\right] ;[\mathrm{Br}] /\left[\mathrm{Cl}^{-}\right] ; \mathrm{ICB}$ (Índice de Cambio de Bases) e outros (CUSTÓDIO et al., 1983).

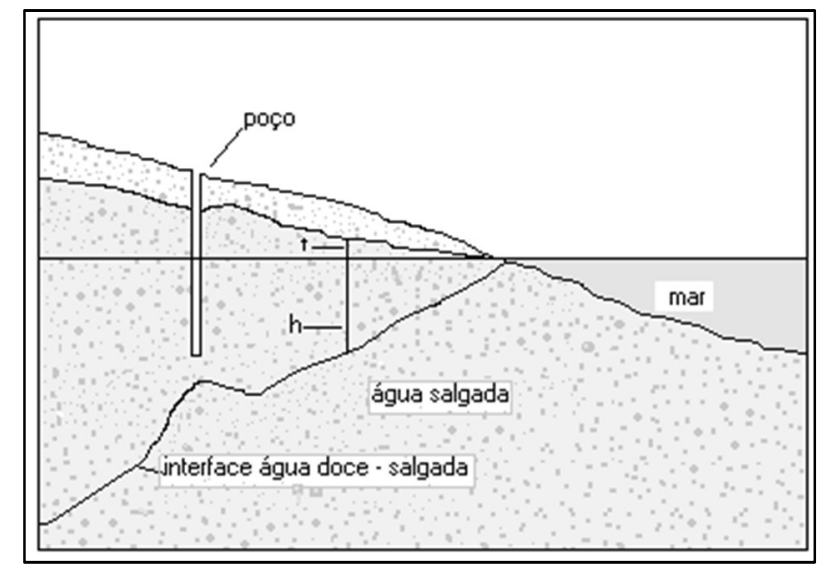

Figura 2: Interfase água doce e água do mar.

\section{Aquífero costeiro de Icapuí}

O aquífero de Icapuí pertence a Bacia hidrográfica do Atlântico Sul-N/NE na Sub-bacia hidrográfica do Rio Jaguaribe, com 68 poços cadastrados na base de dados do Sistema de Informações de Águas Subterrâneas - SIAGAS; destes, apenas 35 ativos, de acordo com o mesmo órgão. 0 fluxo subterrâneo do local é regulado pelas lagoas e lagunas, e a variação de maré, tem como meio natural de controle, banco de algas e os estuários e, se encontram dispostas ao longo da planície costeira, misturando água doce e água salgada. Lagos interdunares, observadas no campo de dunas e, lagoas costeiras, formadas entre sulcos e cavas dos cordões litorâneos nos terraços marinhos holocênicos, sofrem variação de nível d'água sazonal, durante os períodos de chuva, janeiro a maio, e estiagem, agosto a dezembro.

Meireles et al. (2012) afirma a tendência de as lagoas sobre os terraços marinhos serem salobras, provavelmente por conexão com a cunha salina, e por observarem dados morfológicos como: proveniência de sedimentos das paleofalésias; hidrodinâmica relacionada com a aportação de água doce do aquífero (nascentes e olhos d'água dos "morros" entre Ibicuitaba e a Serra da Mutamba); e os eventos de mudanças do nível do mar.

Ainda como exemplo, Meireles et al. (2012) relata ainda o estuário da Barra Grande, onde o manguezal é mais desenvolvido, devido o aporte de água doce (proveniente do exutório da paleofalésia), relacionando-o ao aquífero. Sua vegetação, sedimentos e morfologia são comparáveis com sistemas fluviomarinhos. Das reservas subterrâneas de Icapuí, observa-se uma dependência com a pluviometria, fluxo de água superficial e a capacidade de permeabilidade da zona insaturada. 
A relação entre a composição química da água com os processos e reações no ambiente de subsuperfície é objeto de estudo da Hidrogeoquímica. A sua composição está diretamente dependente da rocha por qual percola, logo, conhecer as interações água/rocha por meio dos processos físico-quimicos e biológicos, adicionando a isso a hidrogeologia, o clima e as fontes de poluição, permite determinar a qualidade da água e o uso adequado da mesma (MESTRINHO, 2008).

\section{Vulnerabilidade de um Aquífero}

Vulnerabilidade é um conjunto de características inerentes aos estratos sedimentares que se encontram entre a superfície do solo e a zona saturada, as quais determinam a susceptibilidade da área em sofrer com as mudanças físicas e químicas ocasionadas por contaminantes que são, serão ou poderão atuar na zona vadosa (HIRATA et al., 2008). O solo é um dos maiores defensores de aquíferos contra este tipo de contaminação. Além de localizar-se entre a carga poluente e a zona saturada, possui características bio-físicoquímicas (mecanismos de sorção, troca catiônica, precipitação, biodegradação, etc.) que induzem a degradação de muitas substâncias e micro-organismos patogênicos antes que eles alcancem o aquífero (FEITOSA, 2008).

O risco de contaminação é a probabilidade de uma água em ser contaminada, alcançando teores acima dos padrões de potabilidade estabelecidos. O grau do risco depende da interação entre as características das cargas contaminantes - aplicação, volume, extensão, intensidade, composição e duração - e, da vulnerabilidade do sistema (MESTRINHO, 2011). Foster et al. (1988) define o conceito de perigo de contaminação das águas subterrâneas como a interrelação entre a vulnerabilidade do aquífero e uma carga contaminante já existente.

A capacidade de atenuação da área ao sofrer efeitos adversos de cargas através da integração de atributos lito e hidrogeológicos nos capacita a determinar a vulnerabilidade de uma área (Tavares et al. 2009). Entretanto, na prática, observa-se que muitos dos fatores ou não estão disponíveis ou são de difícil determinação, assim, a avaliação da vulnerabilidade de um aquífero pode ser realizada através de vários métodos, mas o GOD (FOSTER et al. 1988) é considerado o mais prático deles (MONTEIRO, 2002).

As informações necessárias à aplicação deste método são compostas por dados hidrogeológicos inerentes ao aquífero estudado, referentes aos seguintes fatores: G - grau de confinamento do aquífero (Groundwater Hydraulic Confinement), que sãolassificados em: confinado, semiconfinado ou livre; $\mathrm{O}$ ocorrência e natureza composicional da zona não saturada (grau de consolidação e natureza litológica) (Overlying Strata); e D - distância da superfície até o nível estático d'água (Depth to Groundwater Table).

A cada variável é atribuído um valor gradacional de 0 a 1 que, multiplicados entre si, definem o grau de vulnerabilidade do aquífero, conforme se nota na figura 3. O zoneamento da vulnerabilidade e sua representação cartográfica, focando nas áreas críticas, pode auxiliar na identificação das prioridades de políticas públicas. 


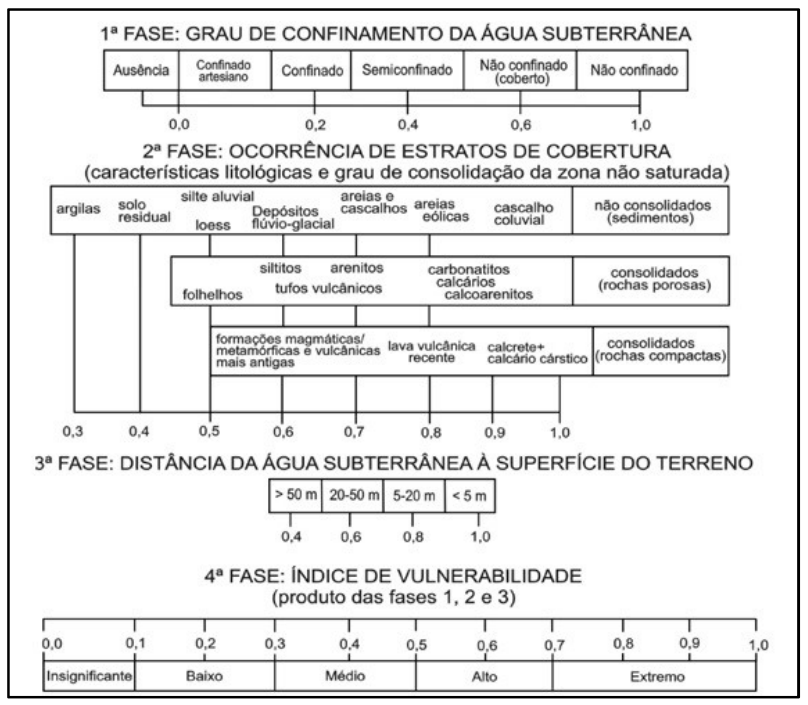

Figura 3: Sistema GOD de avaliação da vulnerabilidade do aquífero à contaminação.

\section{Aspectos Socioeconômicos}

De acordo com os dados do último censo oficial (IBGE, 2010), a maior parte da população icapuiense, 68,54\%, mora na zona rural. Dos 18.392 habitantes, 68,49\% são considerados potencialmente ativos, por estarem na faixa etária de 15-64 anos (IPECE, 2016). A economia local tem sua base na agricultura, culturas como caju, coco-da-Bahia, cana-de-açúcar, mandioca, milho, feijão e aspargo, e também na aquicultura, por meio dos cultivos de camarão, algas e da pesca da lagosta. A atividade pesqueira envolve quase $90 \%$ das famílias do local e na sua grande maioria envolvidos com a cadeia produtiva da lagosta (MONTEIRO, 2010).

O setor industrial consta com três indústrias de produtos alimentares. A extração de petróleo pela PETROBRÁS na Fazenda Belém, e o setor do turismo aproveitando a extensa faixa litorânea, como as praias: Retiro Grande, Ponta Grossa, Redonda, Perobas, Picos, Barreira, Requenguela, Barra Grande, Quitérias, Tremembé, Melancias, Praia de Arrombado e Manibu, sendo o setor de serviços, com 44,15\%, a maior contribuição para o PIB do município e, a maioria dos empregos, quase 79\%, na agropecuária (IPECE, 2016).

Em Icapuí, o Índice de Desenvolvimento Humano Municipal (IDHM), que ajusta o IDH global ao contexto brasileiro usando os dados do censo nacional, mas mantém como objeto de análise as dimensões do IDH: vida longa e saudável, acesso ao conhecimento e padrão de vida, apresentou um crescimento de 104,65\% entre o primeiro relatório de $1991(0,301)$ e o produzido em $2010(0,616)$, colocando o município na faixa do IDHM médio.

Ressaltando que o índice varia de zero (nenhum desenvolvimento humano) até 1 (desenvolvimento humano total), sendo os países classificados: IDH baixo, de 0 a 0,499; IDH médio de 0,500 a 0,799; e, IDH alto de 0,800 a 1. A análise dos resultados desagregados por componentes do IDHM (Tabela 1) apresenta uma evolução significativa nos resultados referentes ao fator educação, passando de 0,097 em 1991 para 0,541 em 2010, de forma contrária, foi observado, no mesmo período, um crescente com bastante timidez na renda. O que justifica o índice de quase $20 \%$ da sua população considerados extremamente pobre (renda per capita mensal de até R\$ 70,00) (IPECE, 2016). 
Tabela 1: Evolução do IDHM e seus componentes para Icapuí/CE (1991 a 2010).

\begin{tabular}{|c|c|c|c|}
\hline IDHM e seus componentes & 1991 & 2000 & 2010 \\
\hline IDHM Educação & 0,097 & 0,338 & 0,541 \\
\hline$\%$ de 18 anos ou mais com ensino fundamental completo & 7,52 & 19,37 & 38,67 \\
\hline$\%$ de 5 a 6 anos na escola & 32,55 & 89,96 & 99,03 \\
\hline \% de 11 a 13 anos nos anos finais do fundamental ou com ensino fundamental completo & 10,38 & 51,92 & 77,45 \\
\hline \% de 15 a 17 anos com fundamental completo & 1,30 & 20,89 & 50,94 \\
\hline$\%$ de 18 a 20 anos com médio completo & 0,00 & 16,03 & 27,99 \\
\hline IDHM Longevidade & 0,578 & 0,650 & 0,757 \\
\hline Esperança de vida ao nascer (em anos) & 59,67 & 64,00 & 70,44 \\
\hline IDHM Renda & 0,488 & 0,498 & 0,572 \\
\hline Renda per capita & 166,95 & 177,85 & 280,79 \\
\hline
\end{tabular}

\section{Localização da área de estudo}

O município de Icapuí, ilustrado na figura 4, fica no extremo leste do estado do Ceará, entre as coordenadas geográficas longitudinais $39^{\circ} 30^{\prime} \mathrm{W}$ e $37^{\circ} 00^{\prime} \mathrm{W}$ e latitudes $05^{\circ} 00^{\prime} \mathrm{S}$ e $03^{\circ} 30^{\prime} \mathrm{S}$, distante, em linha reta, 166 km da capital do Estado do Ceará, Fortaleza. Limítrofe ao norte e ao leste com o Oceano Atlântico, ao sul e oeste com o município de Aracati-CE e, com o Estado do Rio Grande do Norte, também ao sul (IPECE, 2016). Compreende $28,5 \%$ da área total da Plataforma Continental adjacente ao Estado do Ceará (MEIRELES, 2012).

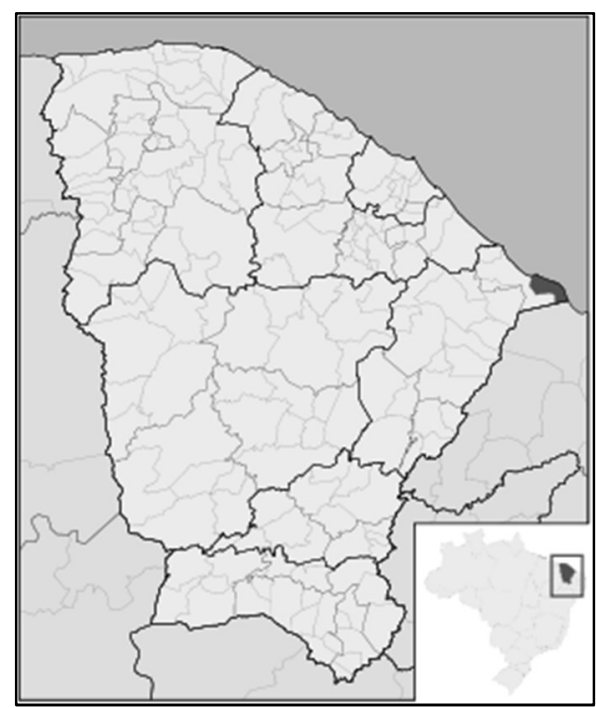

Figura 4: Área de localização

Seu território se estende ao longo de $64 \mathrm{~km}$, com uma área de $423,4 \mathrm{~km}^{2}$ e uma densidade demográfica de 43,43hab/ $\mathrm{km}^{2}$, com um litoral de $40 \mathrm{~km}$ e, uma população estimada em 2015 de 19.418habitantes (IPECE, 2016). O acesso, via terrestre, para o município de Icapuí, com saída de Fortaleza, pode ser feito pela CE-040 até a cidade de Aracati, e então pegar a BR-304 até a CE-261 (conhecido como triângulo). Outra via pode ser por meio da BR-116 até localidade conhecida como Boqueirão do Cesário (pertencente a Beberibe) e tomar a BR-304, passar por Aracati e entrar no acesso a Icapuí - CE-261.

\section{Caracterização Física de Icapuí: Geologia}

A geologia da costa do Ceará foi dividida em: Sedimentar Terciário/Quaternário (representado por clásticos continentais que cobrem discordantemente grande parte dos sedimentos mesozoicos, por exemplo, 
o Grupo Barreiras), cobertura Mesozoica/Paleozoica (representada por sedimentos clásticos e carbonáticos da parte emersa da Bacia Potiguar, pode-se citar a Formação Gangorra) e o embasamento Pré-Cambriano (corresponde a uma ampla região de dobramentos, chamada Nordeste Oriental, proveniente da evolução de uma zona geossinclinal em mosaico, estabelecida no final do pré-cambriano, como o Maciço de Santa Quitéria) (FREIRE, 1985; FREIRE et al., 2004).

Sobrepostas ao embasamento, ocorrem rochas sedimentares atribuídas ao Grupo Barreiras, de idade de miocênica superior a pleistocênica, distribuem-se como uma faixa de largura variável (máximo de 30Km em direção ao interior) acompanhando a linha de costa e a retarguada dos sedimentos eólicos antigos e atuais. Litologicamente, apresenta na sua formação sedimentos areno-argilosos, não ou pouco litificados, de cor avermelhada, creme ou amarela, muitas vezes de aspecto mosqueado. Sua granulação varia de fina a média.

Em estudo litoestratigráfico da região feito por Sousa (2002), ao definir um cenário das ocorrências nas falésias costeiras de Icapuí e leste de Aracati, observou-se o domínio, nas falésias, de rochas siliciclásticas, na base e na parte superior, das formações: Barreiras (base), Potengi (topo) e, já em Aracati, Tibau (base). Com presença localizada, a oeste de Ponta Grossa, de carbonatos na base das falésias oriundos da Formação Jandaíra, unidade mais antiga. Potengi - sucessão areno-quartzosa, com pouca argila, sem estrutura interna, com coloração amarelo-avermelhada, tornando-se mais escura em direção a costa. A variação de cor está associada ao processo de laterização. Barreiras - arenitos médios a sílticos-argilosos, com coloração variando de amarelo, roxo e vermelho, em alguns casos mostrando bastante oxidada (óxido de ferro)

A planície costeira de Icapuí, está inserida no bioma Caatinga, com complexos vegetacionais litorâneos específicos, amplamente representados pela mata de tabuleiro e ecossistema manguezal. Composta por dois sistemas fluviomarinhos, a saber: Barra Grande e Arrombado. Na Barra Grande, situado em frente da cidade de Icapuí, onde a atividade pesqueira se faz presente com o porto de barcos pesqueiros e lagosteiros. Arrombado, mais ao leste da planície, atividade extrativista mineral, produção de sal, e carcinicultura, são diretamente notadas pelas diferentes formas de conservação do mangue (MEIRELES et al., 2012).

O Tabuleiro litorâneo é o relevo predominante do município e, quase sempre, encontra-se coberto por dunas antigas, Formação Potengi (SOUSA, 2002). Seu limite interior marca o contato entre sedimentos tipicamente continentais (inconsolidados, arenosos e de coloração variegada) com os da planície costeira, delimitado por uma falésia morta com aproximadamente $30 \mathrm{~km}$ de extensão. Quando se aproxima do litoral, é representado pelas falésias vivas. Os solos principais são: Areias Quartzosas Distróficas, Areias Quartzosas Marinhas e Latossolo Vermelho-Escuro (IPECE, 2016).

\section{Clima}

O litoral de Icapuí, não diferente de outros municípios do litoral leste do Estado do Ceará, possui as maiores medidas de precipitações pluviométricas, em média da série histórica, registradas no período 
chuvoso, de janeiro a maio, com destaque para os meses de março e abril, que no período entre 1988 e 2015 , suas médias históricas, foram de $223,46 \mathrm{~mm}$ e $225,83 \mathrm{~mm}$, respectivamente.

O clima é Tropical Quente Semiárido Brando, com temperaturas em média de $26-28^{\circ} \mathrm{C}$ (IPECE, 2016), pluviosidade anual total, com média de 914,62mm. A chamada Zona de Convergência Intertropical (ZCIT) é a principal responsável pelas chuvas do período e, com o deslocamento da mesma, na sequência dos meses, na direção do hemisfério norte, observa-se um período de estiagem. A menor média, em torno de 2,21mm, é verificada no mês de setembro, junto com outubro são os de menores pluviosidades. Neste semestre do ano apenas $10 \%$ da precipitação anual é vista nos registros da série histórica anteriormente citada. Com relação à temperatura média mensal, foram registradas oscilações térmicas com médias que variam em torno de 27으, com máximas entre 31으 C a 32드 (MEIRELES et al. 2012).

Os ventos no litoral cearense, tem direções predominantes de SE, ESE, E e NE. As médias de velocidade chegam a superar os $4,5 \mathrm{~m} / \mathrm{s}$, sendo que no período de estiagem, ou seja, no segundo semestre, os ventos são mais intensos e, pode ultrapassar a velocidade de $11 \mathrm{~m} / \mathrm{s}$, com o predomínio dos ventos de SE. No início da estação chuvosa, com a chegada da ZCIT, registram-se mudanças na direção dos ventos, passando a predominar os de NE.

\section{Caracterização da Biota de Icapuí}

Os ecossistemas de Icapuí são constituídos por campos de dunas, manguezais, falésias, carnaubais, lagunas, tabuleiros, etc. Inserida no bioma Caatinga, com complexos vegetacionais litorâneos específicos (SANTOS, 2012), além de conter o segundo maior banco de algas do Brasil. No ecossistema manguezal (Floresta Perenifólia Paludosa Marítima), as espécies vegetais arbóreas principais são: o mangue dos tipos vermelho, verdadeiro ou sapateiro (Rhizophora mangle), o mangue manso, branco ou rajadinho (Laguncularia racemosa), o canoé, preto ou síriba (Avicennia germinans e Avicennia schaueriana) e o mangue ratinho ou botão (Conocarpus erecta).

No apicum, o bredo do mangue (Batis maritima) e a beldroega (Portulaca oleracea) se destacam. A presença do bugi (Dalbergia hecastophylum), como espécie arbustiva, e plantas anfíbias, representadas pela samambaia do mangue (Acrostichum aureum) e pela tabuba (Thypha domingensis) se faz notada nos contatos do manguezal com os cursos de água doce ou nas proximidades de ressurgências hídricas. Nas Matas de Tabuleiro Litorâneo, destaque no extrato vegetal para a imburana (Cammiphora leptophleos), jucá (Caesalpinea ferrea), catingueira (Caesalpinea bracteosa), juazeiro (Ziziphus joazeiro) e outras.

Nas áreas mais úmidas com presença de lagoas e de influência marinha, pode-se destacar, apesar da degradação, a formação da floresta mista dicótilo-palmácea (presença de carnaubais, Copernicia prunifera, por exemplo). Nas áreas de pós-praia e terrenos subsequentes, a restinga é destaque com a salsa (Ipomoea pes-caprae), o pinheirinho da praia (Ramirea maritima) e o pirrichiu (Sesuvium portulacastrum). O coqueiral, presente sobre os terraços marinhos, apesar de não ser uma espécie nativa, adaptou-se ao solo predominantemente arenoso (Neossolos Quartzoarênicos) e bem drenado, agregando valor paisagístico e econômico, por meio do seu fruto, ao município. 
Na sua fauna, o destaque é a presença do peixe-boi marinho, também conhecido como manatee, que por ser um animal herbívoro, tem nas algas da localidade a sua principal refeição. Após a lagosta, principal recurso pesqueiro da região, os pescadores nativos citam como fonte de renda a pesca dos peixes: sirigado, cavala, camurupim, ariacó, carapicu e tibiro (PINTO et al., 2013).

A sua importância ambiental para o Ceará foi reconhecida por meio de sua classificação nos estudos realizados durante o Zoneamento Econômico-Ecológico Costeiro do Estado do Ceará como polo de interesse ecológico. O que repercute, tanto na definição do perfil dos empreendimentos que ali podem ser implantados como no fato de que as licenças ambientais para tais empreendimentos estão sujeitas a um controle mais rigoroso do que nas demais áreas do Estado.

\section{METODOLOGIA}

O material pesquisado faz parte de acervos da Biblioteca de Ciências e Tecnologia da UFC, e de sites especializados em publicações científicas e de instituições estatais (FUNCEME, IPECE, IBGE). Os dados de valores ambientais, foram registrados, por meio de fotos e visitas de campo, no período de março de 2014 a junho de 2016, permitindo assim a construção de uma matriz adaptada de Leopold (1971), sendo que a adaptação tem como referência, importantes autores, como Mota (2002), Rocha (2005), Richieri (2006) e Schneider (2011), buscou-se assim, desenvolver uma matriz que apresentasse da forma mais direta possível entre as ações da exploração e explotação do aquífero de Icapuí sobre as diversas características do meio, seja ele antrópico, biótico ou abiótico.

A construção da matriz desenvolveu-se em 3 etapas: na primeira, foram identificadas as atividades potencialmente impactantes ao meio ambiente e os aspectos ambientais existentes que podem ser afetados por essas atividades; em seguida, cada cruzamento proposto pela matriz foi ponderado quanto a magnitude e importância; por fim, considerou-se a soma dos pesos determinados para os atributos extensão, periodicidade e intensidade. Já a importância é o resultado da soma dos valores dos atributos de ação, ignição e criticidade.

Tabela 2: Valores da importância para seus atributos ambientais e ponderação equivalente

\begin{tabular}{|l|l|}
\hline IMPORTÂNCIA = AÇÃO + IGNIÇÃO + CRITICIDADE & VALOR PONDERADO \\
\hline $\begin{array}{l}\text { AÇÃO (Peso: } 1 \text { a 4) } \\
\text { Número de efeitos que a ação causa }\end{array}$ & $\begin{array}{l}\text { Primária (+1): } 1 \text { causa } \rightarrow 1 \text { efeito; } \\
\text { Secundária (+2): } 1 \text { causa } \rightarrow 2 \text { efeitos; } \\
\text { Terciária (+3): } 1 \text { causa } \rightarrow 3 \text { efeitos; } \\
\text { Enésima (+4): } 1 \text { causa } \rightarrow \text { efeitos. }\end{array}$ \\
\hline $\begin{array}{l}\text { IGNIÇÃO (Peso: } 1 \text { a 3) } \\
\text { Tempo que a ação leva para aparecer. É o intervalo de } \\
\text { tempo entre a ação e o efeito }\end{array}$ & $\begin{array}{l}\text { Imediata (+1): causa } \rightarrow \text { efeito simultâneo; } \\
\text { depois; } \\
\text { Longo Prazo (+2): causa } \rightarrow \text { efeito surge simultâneo e/ou tempo } \rightarrow \text { efeito surge muito tempo depois, } \\
\text { concomitante ou não com os casos anteriores. }\end{array}$ \\
\hline $\begin{array}{l}\text { Nível de relação entre a ação e o efeito que ela provoca } \\
\text { Baixa (+1): baixo nível de ação entre os fatores causa } \rightarrow \text { efeito; } \\
\text { Média (+2): médio nível de ação entre os fatores causa } \rightarrow \text { efeito; } \\
\text { Alta (+3): alto nível de ação entre os fatores causa } \rightarrow \text { efeito. }\end{array}$
\end{tabular}

O resultado da ponderação de atributos não é uma medida do impacto, no sentido físico de uma grandeza que possa servir de padrão para avaliar outras do mesmo gênero, mas uma apreciação qualitativa 
da importância do impacto (SÁNCHEZ, 2006). Nas tabelas 2 e 3 estão expostas as ponderações de cada atributo para a formação do peso final.

Tabela 3: Valores da magnitude para seus atributos ambientais e ponderação equivalente

\begin{tabular}{|l|l|}
\hline MAGNITUDE = EXTENSÃO + PERIODICIDADE + INTENSIDADE & VALOR PONDERADO \\
\hline $\begin{array}{l}\text { EXTENSÃO (Peso: } 1 \text { a 4) Tamanho da ação ambiental ou da área de } \\
\text { influência real. }\end{array}$ & $\begin{array}{l}\text { Pequena extensão (+1); } \\
\text { Média extensão (+2); } \\
\text { Grande extensão (+3); } \\
\text { Muito grande extensão (+4). }\end{array}$ \\
\hline $\begin{array}{l}\text { PERIODICIDADE (Peso: } 1 \text { a 3) Duração do efeito da ação. Tempo que o o } \\
\text { efeito demora a terminar. }\end{array}$ & $\begin{array}{l}\text { Ação temporária (+1): cessa quando pára a ação; } \\
\text { Ação variável (+2): não se sabe quando termina o } \\
\text { efeito após cessar a ação; } \\
\text { Ação permanente (+3): não cessa mesmo parando a } \\
\text { ação. }\end{array}$ \\
\hline $\begin{array}{l}\text { INTENSIDADE (Peso: } 1 \text { a 3) Exuberância da ação impactante. Relação da da } \\
\text { dimensão da ação com a atividade. }\end{array}$ & $\begin{array}{l}\text { Média (+2): média ação impactante; } \\
\text { Alta (+3): alta ação impactante. }\end{array}$ \\
\hline
\end{tabular}

A última etapa consiste em cruzar o somatório dos valores obtidos para magnitude e importância, multiplicando um pelo outro, obtendo-se assim um índice final. Com esse índice foi possível identificar as atividades mais impactantes ao meio ambiente. Para o estudo da vulnerabilidade seguiu-se o método GOD (FOSTER et al., 1988), onde se atribui valores às seguintes variáveis: tipo de confinamento do aquífero, geologia ou litologia da zona não saturada e, profundidade do nível estático d'água ou teto do aquífero confinado.

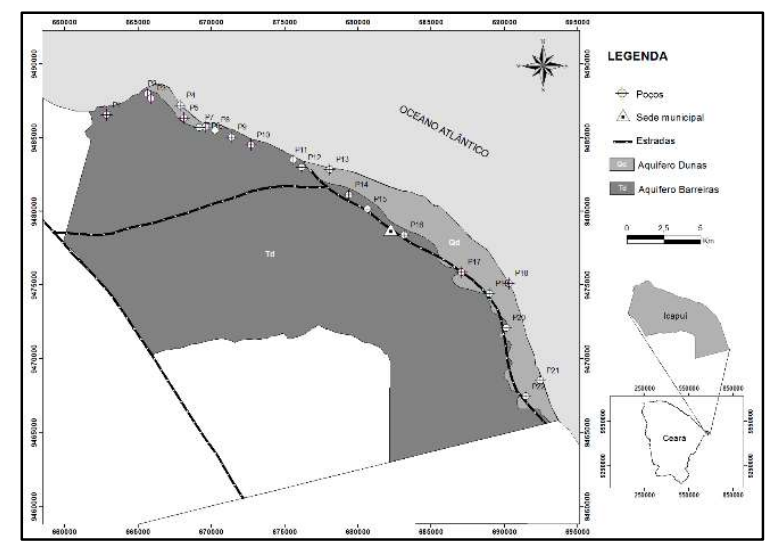

Figura 5: Mapa de localização dos poços

\section{RESULTADOS E DISCUSSÕES}

Propõem-se as matrizes com os seus aspectos qualitativos, no caso da valoração ambiental e, quantitativos, na matriz de Leopold. A utilização de dados quali-quantitativos, permite a análise sistêmica do ambiente e suas variações nos campos mensuráveis e intangíveis da biodiversidade e seus atores. Após a adaptação da matriz de Leopold, observa-se que a atividade hierarquicamente mais impactante foi durante a construção dos poços. Tal atividade envolve tanto contratação de técnicos especialistas, inclusive de outras cidades do estado, como mão-de-obra local, compra e aluguel de maquinários, aumento na hospedagem das pousadas e hotéis, gera fluxo de capital ao comércio local, proporciona investimentos na malha elétrica e hidráulica e outros mais. 


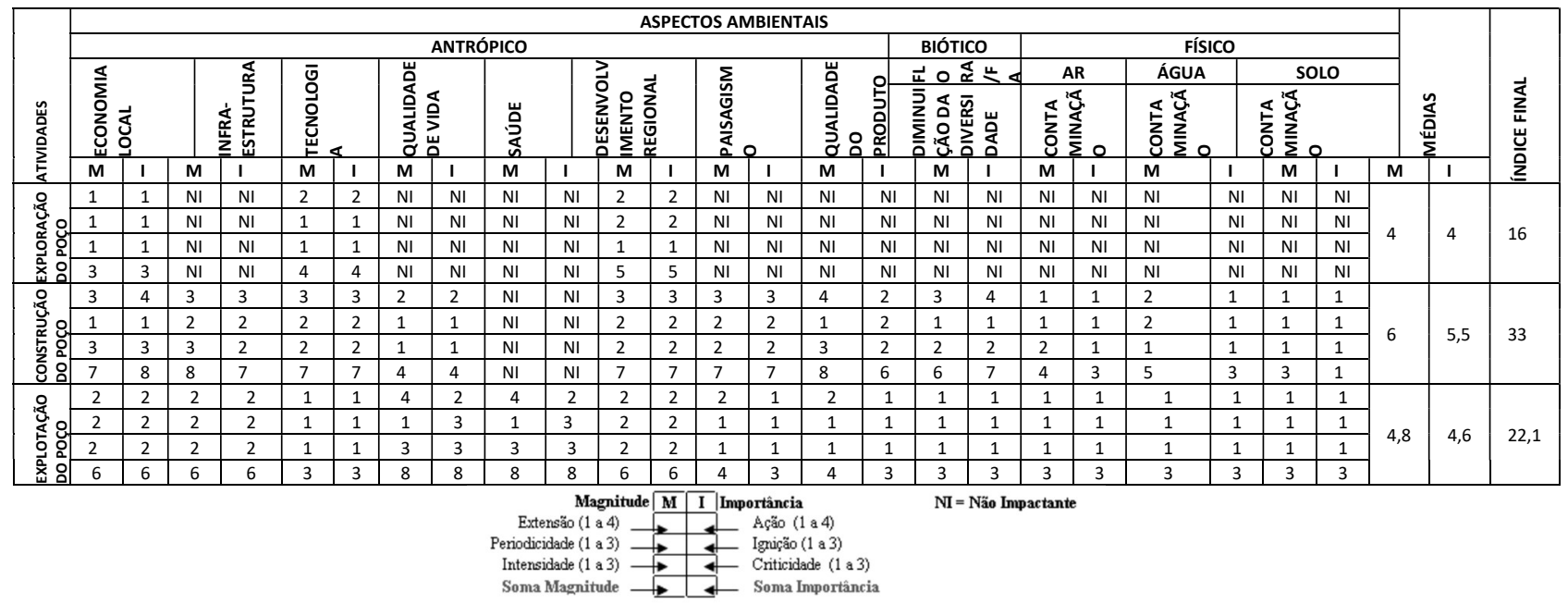

Figura 6: Matriz adaptada de Leopold mostrando os atributos de magnitude e importância

A litologia da zona vadosa é classificada como grau 0,7 por possuir sedimentos inconsolidados, formados por areia quartzosa, aluviões, areia fina, arenito e argilosos, aquífero livre (coberto). Além deste, foi tomada por base, também, algumas descrições de perfis de poços apresentando dados de coordenadas, níveis estáticos e dinâmicos, litologia e ano de construção, implantados pela SOHIDRA - Superintendência de Obras Hidráulicas do Estado do Ceará, conseguidos junto ao site da CPRM.

Tabela 6: Vulnerabilidade à contaminação do aquífero em Icapuí/CE

\begin{tabular}{|c|c|c|c|c|c|}
\hline \multirow[t]{2}{*}{ POÇO } & \multirow{2}{*}{$\begin{array}{l}\text { PARÂMETROS GOD } \\
\text { UNIDADE AQUÍFERA }\end{array}$} & \multirow[b]{2}{*}{ LITOLOGIA } & \multirow[b]{2}{*}{ PROFUNDIDADE } & \multicolumn{2}{|c|}{ RESULTADOS } \\
\hline & & & & VALOR & CLASSIFICAÇÃO \\
\hline 01 & 0,6 & 0,7 & 0,7 & 0,294 & BAIXA \\
\hline 02 & 0,6 & 0,7 & 0,9 & 0,378 & MÉDIA \\
\hline 04 & 0,6 & 0,7 & 0,9 & 0,378 & MÉDIA \\
\hline 06 & 0,6 & 0,7 & 0,8 & 0,336 & MÉDIA \\
\hline 07 & 0,6 & 0,7 & 0,7 & 0,294 & BAIXA \\
\hline 12 & 0,6 & 0,7 & 0,8 & 0,336 & MÉDIA \\
\hline 13 & 0,6 & 0,7 & 0,9 & 0,378 & MÉDIA \\
\hline 14 & 0,6 & 0,7 & 0,9 & 0,378 & MÉDIA \\
\hline 16 & 0,6 & 0,7 & 0,9 & 0,378 & MÉDIA \\
\hline 18 & 0,6 & 0,7 & 0,9 & 0,378 & MÉDIA \\
\hline 21 & 0,6 & 0,7 & 0,9 & 0,378 & MÉDIA \\
\hline 22 & 0,6 & 0,7 & 0,8 & 0,336 & MÉDIA \\
\hline
\end{tabular}

Os poços localizados nas coordenadas plotadas em 01 e 07, possuem uma cota topográfica maior, o que relaciona uma maior profundidade do poço e distanciamento do lençol freático, por seu turno, menor risco de contaminação antrópica e, além do mais, possuem na composição do solo, argila que, podem capturar os contaminantes, por meio de trocas catiônicas realizadas no sedimento pela matéria orgânica e, caracterizando-se por sua baixa permeabilidade, dificultando a percolação dos mesmos.

\section{CONCLUSÕES}

A explotação da água subterrânea, associada a recente instalação de rede de esgotamento sanitário, pode causar um rebaixamento do solo (subsidência) e, prejudicar a estrutura de prédios antigos, assim como, contaminação do lençol freático. Por meio de antigas fossas sépticas, caso não sejam devidamente desativadas ou por vazamentos em paredes da mesma danificadas. 
Torna-se urgente informar aos gestores públicos para o risco do aumento de conflitos sociais, pelo uso da água. Conflitos futuros causados não só pela alteração da qualidade hídrica, como também, pela escassez da mesma, especialmente, nos períodos de estiagem prolongada, gerando, uma provável disputa entre as atividades existentes, desde as mais recentes, até as tradicionalmente desenvolvidas no município. Fora isto, conflitos que podem advir, em função de potenciais riscos, quanto à garantia da oferta de água para o abastecimento das zonas urbana e rural de Icapuí.

Investimentos na rede de saneamento do município, principalmente na coleta de esgoto, visando a diminuição de doenças veiculadas a água e/ou de notificação compulsória, torna-se primordial, não só pela qualidade de vida como, também, pela manutenção de um ambiente rico e sustentável. Mapear os cenários e plotar atividades ainda possíveis de implantar no município, respeitando a sua classificação no zoneamento estadual, como polo de interesse ecológico. Para tal, faz-se necessário uma gestão ambiental estratégica, por meio de avaliação, com diagnóstico técnico e relatórios de domínio público.

Encontram-se hoje, atividades de turismo ambiental, como trilhas ecológicas, passeios de embarcações artesanais (jangadas), fotografia, mergulho e outras, aproveitando o movimento brando da maré, protegida por um extenso manguezal e, presença de animais marinhos endógenos (por exemplo, manatee). Atividades atuais, aproveitando riquezas naturais e saber popular, devem ter maior participação de órgão públicas e empresas privadas, não só por meio de projetos, como 'De olho na água' (PETROBRÁS) ou 'Festival da Lagosta' (GDTUR- Associação Grupo de Desenvolvimento de Turismo em Icapuí com apoio do SEBRAE-CE, Serviço Brasileiro de Apoio às Micro e Pequenas Empresas), mas também com linhas de crédito específicas e consultorias agregadas, para ampliar e incentivar o empreendedorismo na população local.

\section{REFERÊNCIAS}

ALIEVI, A. A.; PINESE, J. P. P.; CELLIGO, A.. Inventário das áreas de concentração de poços tubulares na zona urbana de Londrina (PR) e implicações ambientais. ACTA Geográfica, Boa Vista, v.6, n.13, p.77-92, 2012.

AUGUSTO, L. G. S.; GURGEL, I. G. D.; CÂMARA NETO, H. F.; MELO, C. H.; COSTA, A. M.. O contexto global e nacional frente aos desafios do acesso adequado à água para consumo humano. Ciência \& Saúde Coletiva, v.17, n.6, p.1511-1522, 2012.

BAIRD, C.; CANN, M.. Química Ambiental. 4 ed. Porto Alegre: Bookman, 2011.

BOCANEGRA, E.; SILVA JUNIOR, G. C.; CUSTODIO, E.; MANZANO, M.; MONTENEGRO, S.. State of knowledge of coastal aquifer management in South America.

Hydrogeology Journal, v.18, p.261-267, 2010.

CUSTODIO, E.; LLAMAS, M. R.. Hidrologia Subterrânea. 2 ed. Barcelona: Ômega, 1983.

FEITOSA, F. A. C.. 2008. Hidrogeologia: conceitos e aplicações. 3 ed. Rio de Janeiro: CPRM, 2008.

FOSTER, S.; HIRATA, R.; Groundwater pollution risk assessment: a metthodology based on available data. Lima: WHO, 1988.
FREIRE, G. S. S.. Geologia marinha da plataforma continental do Ceará. Dissertação (Mestrado em Geologia) Universidade Federal de Pernambuco, Recife, 1985.

FREIRE, G. S. S.; GOMES, D. F.; LIMA, S. F.; MAIA, L. P.; LACERDA, L. D.. Geochemistry of Continental Shelf Sediments of the Ceará Coast, North-Eastern Brazil. In: LACERDA, L. D.; SANTELLI, R. E.; DUURSMA, E.; ABRÃO, J. J.. Environmental Geochemistry in Tropical and Subtropical Environments. Berlin: Springer-Verlag, 2004. p.365-377.

HIRATA, R.; FERNANDES, A. J.. Vulnerabilidade à poluição de aquíferos. In: FEITOSA, F. A. C.. Hidrogeologia: Conceitos e aplicações. 3 ed. Rio de Janeiro: CPRM, 2008. p.405-424.

IBGE. Instituto Brasileiro de Geografia e Estatística. Censo demográfico. Rio de Janeiro: IBGE, 2010.

IPECE. Instituto de Pesquisa e Estratégia Econômica do Ceará. Perfil Básico Municipal. Fortaleza: IPECE, 2016.

LACERDA, L. D.; SANTOS, J. A.; MARINS, R. V.; MAIA, S. R. R.; VAISMAN, A. G.. Impacto potencial da emissão antrópica de Cu e Zn sobre a carcinicultura na bacia inferior do Rio Jaguaribe, CE. Revista da ABCC, Candelária, v.6, n.1, 2004. 
LEOPOLD, L. B.; CLARKE, F. S.; HANSHAW, B... A procedure for evaluating environmental impact. Washington: Geological Survey, 1971

MANOEL FILHO, J.. Ocorrência das águas subterrâneas. In: FEITOSA, F. A. C.. Hidrogeologia: Conceitos e aplicações. 3 ed. Rio de Janeiro: CPRM, 2008. p.53-75.

MEIRELES, A. J. A.; SANTOS, A. M. F.. Atlas de Icapuí. Fortaleza: Editora Fundação Brasil Cidadão, 2012.

MESTRINHO, S. S. P.. Curso de classificação, enquadramento e monitoramento de águas subterrâneas. Fortaleza: ABAS, 2011.

MESTRINHO, S. S. P.. Geoquímica das águas subterrâneas. In: FEITOSA, F. A. C.. Hidrogeologia: Conceitos e aplicações. 3 ed. Rio de Janeiro: CPRM, 2008. p.359-379.

MONTEIRO, A. B.. Vulnerabilidade e distribuição espacial dos nitratos no aquífero Barreiras nos bairros de lbura e Jordão Recife - Pernambuco. SIMPÓSIO BRASILEIRO DE RECURSOS HÍDRICOS, 15. Anais. Curitiba: ABRH, 2002.

MONTEIRO, E. A.; ARAUJO, R. C. P.; CASTRO, F. T. C.. Diagnóstico Socioeconômica do Projeto de Alginocultura na Comunidade de Barrinha de Mutamba no Município de Icapuí, Ceará. In: CONGRESSO DA SOCIEDADE BRASILEIRA DE ECONOMIA, ADMINISTRAÇÃO E SOCIOLOGIA RURAL, 48. Anais. Campo Grande: SOBER, 2010

MOTA, S.; AQUINO, M. D.. Proposta de uma matriz para avaliação de impactos ambientais. In: SIMPÓSIO ÍTALO BRASILEIRO DE ENGENHARIA SANITÁRIA E AMBIENTAL, 6. Anais. Vitória: SIBESA, 2002.
PINTO, M. F.; MOURÃO, J. S.; ALVES, R. R. N..

Ethnotaxonomical considerations and usage of ichthyofauna in a fishing community in Ceará State, Northeast Brazil. Journal of Ethnobiology and Ethnomedicine, v.9, 2013.

RICHIERI, S. M. M.. Estudo do impacto das mudanças climáticas globais nos mangues tropicais. Dissertação (Mestrado em Engenharia de Processos Químicos e Bioquímicos) - Escola Mauá de Tecnologia, São Caetano do Sul, 2006

ROCHA, J. S. M.; GARCIA, S. M.; ATAIDES, P. R. V.. Manual de avaliações de impactos e passivos ambientais. Santa Maria: Palloti, 2005

SÁNCHEZ, L. E.. Avaliação de impacto ambiental: conceitos e métodos. São Paulo: Oficina de Textos, 2006.

SCHNEIDER, V. E.. Proposta metodológica para avaliação das ações antrópicas impactantes aplicada a elaboração de planos ambientais municipais. In: CONGRESSO BRASILEIRO DE ENGENHARIA SANITÁRIA E AMBIENTAL, 26. Anais. Porto Alegre, 2011.

SOUSA, D. C.. Litoestratigrafia e deformação cenozoica na região de Icapuí, Ceará, e implicações para a estruturação de campos de petróleo na borda ocidental da bacia potiguar (NE do Brasil). Tese (Doutorado em Geodinâmica e Geofísica) - Universidade Federal do Rio Grande do Norte, Natal, 2002.

TAVARES, P. R. L.; CASTRO, M. A. H.; COSTA, C. T. F.; SILVEIRA, J. G. P.; ALMEIDA JÚNIOR, F. J.. Mapeamento da vulnerabilidade à contaminação das águas subterrâneas localizadas na Bacia Sedimentar do Araripe, Estado do Ceará, Brasil. Revista Escola Minas, Ouro Preto, v.62, n.2, p.227236, 2009. 